Martin Cascio MD, Bernard Pygon MD, Cathleen Bernett BS, Sivam Ramanathan MD

\title{
Labour analgesia with intrathecal fentanyl decreases maternal stress
}

Purpose: Lumbar epidural analgesia (LEA) decreases matemal stress as measured by maternal circulating plasma catecholamine concentrations. Intrathecal fentanyl (ITF) provides effective labour analgesia but its effect on maternal epinephrine (Epi) and norepinephrine (NE) concentrations is not known. This study assesses whether ITF reduces maternal stress in the same manner as conventional LEA.

Methods: Twenty-four healthy women in active labour received either $25 \mu \mathrm{g} \operatorname{TF}(n=12)$ or epidural lidocaine $1.5 \%(n=12)$ for analgesia. Venous blood samples were collected before anaesthesia and at five minute intervals for $30 \mathrm{~min}$ following anaesthesia for the measurement of plasma Epi and NE by high performance liquid chromatography. Matemal blood pressure (BP), heart rate (HR), visual analog scores (VAS) to pain and prunitus were recorded at the same time.

Results: Both ITF and LEA decreased pain VAS scores, maternal BP, and plasma Epi concentrations with only minimal effects on plasma NE concentrations. Intrathecal fentanyl (ITF) and LEA reduced plasma epi to a similar extent, with ITF reducing the levels slightly faster than LEA. Intrathecal fentany(ITF) and LEA reduced plasma Epi concentrations by $52 \%$ and $51 \%$, respectively $(P$ value $<0.01)$.

Conclusion: We condude that ITF is as effective as LEA in producing pain relief in the labouring patient. Intrathecal Fentanyl (ITF) is also capable of reducing matemal plasma epinephrine concentration, thus avoiding the possibly deleterious side effects of excess amounts of this catecholamine during labour.

Objectif : L'analgésie épidurale lombaire (AÉL) diminue le stress matemel déterminé par le dosage des concentrations plasmatiques de catécholamines. Le fentanyl sous-arachnoïdien (FSA) procure une analgésie efficace pendant le travail mais on ne connât pas son influence sur les concentrations maternelles d'épinéphrine (ÉPI) et de norépinéphrine (NÉ). Cette étude visaít à déterminer si le FSA diminuait le stress de la même façon que l'AÉLL.

Méthodes : Vingt-quatre parturientes bien portantes en travail ont reçu pour l'analgésie soit du FSA $25 \mu \mathrm{g}$ $(n=12)$ soit de la lidocaine épidurale 1,5\% $(n=12)$. Des échantillons de sang veineux ont été recueillis avant l'anesthésie et à des intervalles de cinq minutes pendant 30 min après l'anesthésie dans le but de mesurer l'ÉPI et la NÉ plasmatiques par chromatographie en phase liquide à haute performance. En même temps, la pression artérielle (PA), la fréquence cardiaque et les scores d'une échelle visuelle analogique (ÉVA) pour la douleur et le prurit étaient enregistrés.

Résultats : Le FSA et l'AÉL diminuent les scores d'ÉVA, la PA et les concentrations d'ÉPI avec des effets minimes sur les concentrations plasmatiques de NÉ. Le FSA et l'AÉL réduisent également l'ÉPI plasmatique, mais la réduction est un peu plus rapide avec le FSA. Le FSA et I'AÉL diminuent respectivement les concentrations de $51 \%$ et $52 \%(P<0,01)$.

Conclusion : Le FSA est aussi efficace que l'AÉL pour soulager la douleur chez la parturiente en travail. Le fentanyl sous-arachnoïdien diminue aussi les concentrations maternelles d'épinéphrine, protégeant ainsi la parturiente en travail des effets nocifs de concentrations excessives de catécholamines.

From the Department of Anesthesiology and Critical Care Medicine, University of Pittsburgh, School of Medicine, Magee-Wonens Hospital, 300 Halket Street, Pittsburgh, PA 15213, USA

Address correspondence to: Dr. Marin Cascio, Department of Anesthesiology, Magee-Womens Hospital, 300 Halket Strect, Pittsburgh, PA 15213; Phone: 412-641-4260.

Presented at: 70th Annual International Anesthesia Research Society Meering, 1996.

Accepted for publication March 9, 1997. 
$\mathrm{T}$

HE use of intrathecal fentanyl (ITF) is an attractive alternative to epidural local anaesthetics for the relief of labour pain. It may have certain advantages over epidural local anaesthetics including absence of motor blockade, which may occur with epidural local anaesthetics even with the reduced concentrations that are currently used, and more rapid onset of analgesia than epidural local anaesthetics. ${ }^{1,2}$ Labour pain increases maternal anxiety and stress, which correlates with elevated maternal plasma catecholamine concentrations. ${ }^{3,4}$ The raised catecholamine levels have been implicated in causing reduced uterine blood flow, dysfunctional labour and fetal heart rate abnormalities. ${ }^{3}$ Conventional labour epidural analgesia (LEA) with local anaesthetics reduces maternal plasma catecholamine concentrations ${ }^{5}$ which may prevent these undesirable effects of stress. Our aim was to investigate whether ITF decreased maternal plasma concentrations in a fashion similar to LEA.

\section{Methods}

After institutional review board approval, and informed consent, 24 women ASA status I and II, at term in active labour were studied. A \#18G indwelling venous cannula was placed in the antecubital vein at least $20 \mathrm{~min}$ before starting the study for venous blood samples. Maternal blood pressure, and heart rate were recorded by a noninvasive automatic blood pressure device (Dinamap, Critikon, Tampa, Fl 33634). Visual analog scores (VAS) to pain, and pruritus were recorded on a $100 \mathrm{~mm}$ scale by a non-blinded observer. The patient was given $500 \mathrm{ml}$ lactated Ringers iv prior to initiation of analgesia. Patients were randomized into two groups. Group $1(n=12)$ received $25 \mu \mathrm{g}$ ITF for labour analgesia and Group $2(\mathrm{n}=12) 10 \mathrm{ml}$ epidural lidocaine $1.5 \%$.

A combined spinal-epidural (CSE) technique was used in the ITF group. A \#17g Hustead needle was introduced into the epidural space using the loss of resistance technique. A $12.3 \mathrm{~cm} \# 24 \mathrm{~g}$ Sprotte spinal needle (Pajunk Medizintechnologie, Geisingen, Germany) was then passed into the subarachnoid space through the epidural needle. After a free flow of clear cerebrospinal fluid (CSF) was obtained, $0.5 \mathrm{ml}(25 \mu \mathrm{g})$ fentanyl (Elkin-Sinns Cherry Hill, NJ 08003) was injected into the subarachnoid space. The spinal needle was then withdrawn and an epidural catheter inserted 4 $\mathrm{cm}$ into the epidural space. The catheter was aspirated to check for possible inadvertent subarachnoid or intravenous placement. In the LEA group, the epidural space was identified at the $\mathrm{L}_{2-3}$ or $\mathrm{L}_{3-4}$ intervertebral space with the epidural needle and $10 \mathrm{ml}$ plain lidocaine 1.5\% (Astra, U.S.A. Westborough, MA 01581) were injected through the needle in divided doses after which an epidural catheter was inserted $4 \mathrm{~cm}$ into the epidural space. The catheter was aspirated to check for possible inadvertent subarachnoid or intravenous placement. Venous blood samples, visual analog scores, and haemodynamic variables were obtained before (baseline) and at five minute intervals for $30 \mathrm{~min}$ after the injection of the study drug was completed.

Blood samples for norepinephrine and epinephrine assay were collected in glutathione containing tubes placed in ice. The plasma was separated and kept frozen at $-70^{\circ} \mathrm{C}$ until analysis. Prolonged storage, repeated thawing and refreezing were avoided to prevent loss of catecholamines. ${ }^{6}$ The concentrations of norepinephrine and epinephrine in plasma were determined using high performance liquid chromatography with electrochemical detection (HPLC-EC). ${ }^{7}$ The system consisted of a 600E solvent delivery pump (Waters Corp. 34 Maple St. Milford, MA 01757) with a Coulochem II electrochemical detector (ESA, 22 Alpha Rd. Chelmsford, MA 01824). Data were collected and quantified utilizing Millennium 2010 computer software (Waters Corp. 34 Maple St. Milford, MA 01757).

Results were expressed as mean $\pm \mathrm{lSD}$. Postanalgesia haemodynamic data and catecholamines were compared with the corresponding baseline measurement using repeated measures analysis of variance (ANOVA) at $P<0.05$. Visual analog scores were compared using nonparametric methods at $P<0.05$.

\section{Results}

Six patients from the ITF group and seven from the LEA group were receiving oxytocin augmentation at the time of induction of analgesia. Patients' age, height, body weight, parity, and cervical dilatation at the time of analgesia were not different between groups. (Table I )

Visual analog scores to pain (Figure 1) decreased within five minutes of ITF or LEA administration and remained lower than baseline throughout the study.

TABLE I Patient Demographics

\begin{tabular}{lll}
\hline & $I T F(n=12)$ & $\begin{array}{l}\text { Lidocaine } \\
(n=12)\end{array}$ \\
\hline Age $(\mathrm{yr})$ & $24.8 \pm 7.7$ & $27.1 \pm 6.3$ \\
Height $(\mathrm{cm})$ & $161.3 \pm 5.5$ & $164.8 \pm 12.3$ \\
Weight $(\mathrm{kg})$ & $84.8 \pm 16.3$ & $82.3 \pm 20.4$ \\
Baseline cervical dilation $(\mathrm{cm})$ & $4.1 \pm 1.6$ & $3.7 \pm 1.5$ \\
Parity $=0$ & 6 & 5 \\
Parity $>0$ & 6 & 7 \\
Oxytocin before analgesia & 6 & 7 \\
\hline
\end{tabular}

Data (except parity and oxytocin) are means $\pm S D$. 
Maternal systolic, diastolic and mean blood pressure decreased following analgesia in both groups with no differences between groups (Figure 2). These changes in maternal blood pressure did not require treatment in any patient and no abnormality in fetal heart rate tracing occurred in any patient. Maternal heart rate decreased in the ITF group following induction of analgesia (Figure 2). No patient from the LEA group noted pruritus while all patients in the ITF group experienced pruritus, but none required treatment. The VAS scores for pruritus in the ITF group are presented in Figure 1.

Plasma epinephrine concentrations decreased following administration of intrathecal fentanyl or epidural Lidocaine (Figure 3). Plasma epinephrine concentration showed a decrease at five minutes and remained lower than the baseline measurement throughout the study in both groups (Figure 3). Epinephrine concentrations decreased by $45 \%$ from baseline values in the intrathecal fentanyl group at the five minute interval, whereas epinephrine concentrations decreased only $24 \%$ in the epidural lidocaine group. Although, by $30 \mathrm{~min}$, the percent decreases in epinephrine concentrations in the intrathecal fentanyl group and the epidural lidocaine group were comparable, $52 \%$ and $51 \%$ respectively $(P$ value $<0.01)$. Changes in plasma norepinephrine concentrations were less pronounced than those of plasma epinephrine concentrations in both groups (Figure 3). Only the $30 \mathrm{~min}$ measurement in the ITF group and the 20 and $30 \mathrm{~min}$ measurements in the LEA group were increased from the respective baseline measurement ( $P$ value $<0.05$ ).

\section{Discussion}

The use of intrathecal opioids has been gaining popularity for labour analgesia in the last $10 \mathrm{yr}$. It is important to know whether these newer techniques offer other potential benefits besides pain relief. Our data show that intrathecal fentanyl not only offers effective analgesia but is capable of reducing maternal plasma epinephrine levels at least to the same extent as local anaesthetics.

Because repeated venipuncture can cause an increase in plasma catecholamine concentrations, we utilized an indwelling venous cannula to obtain maternal blood samples. ${ }^{8}$ Peripheral tissues can metabolize catecholamines ${ }^{9}$ and, consequently, the sampling site may affect the actual values of catecholamines. ${ }^{10}$ Arterial blood has a higher epinephrine concentration and a lower norepinephrine concentration than does venous blood. ${ }^{9}$ Despite this, many investigators have used venous samples for catecholamine levels in their studies. ${ }^{11}$ According to Dimsdale, ${ }^{11}$ catecholamines

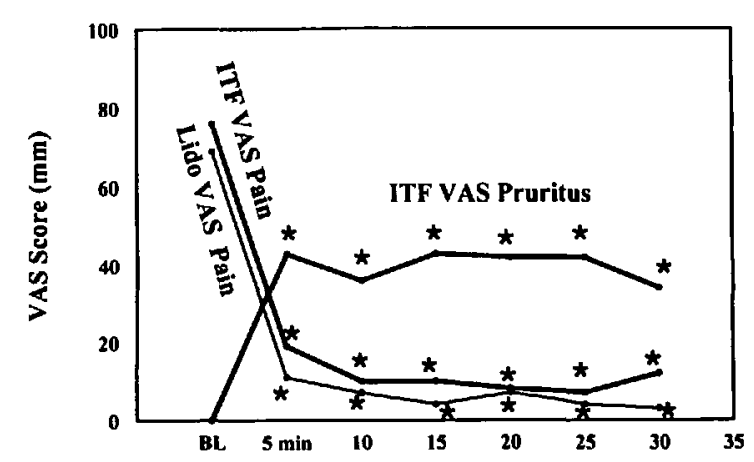

FIGURE 1 Maternal visual analog scale (VAS) for pain and pruritus at baseline (BL) and $5,10,15,20,25$, and 30 min after initiation of analgesia. The intrathecal fentanyl group is indicated as ITF and the epidural lidocaine group as Lido. Data are mean $\pm \mathrm{SD}$.

*significantly different from baseline within the group.

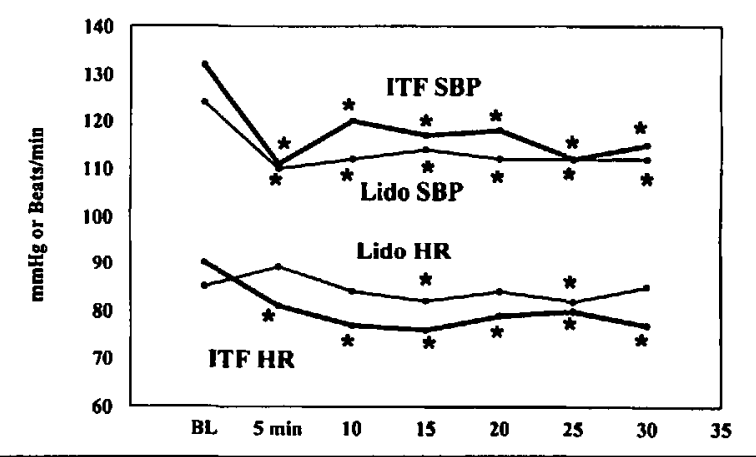

FIGURE 2 Maternal systolic blood pressure (SBP) and heart rate (HR) in mmHG and beats per minute, respectively. Data are mean $\pm \mathrm{SD}$

* significantly different from baseline within the group.

For other abbreviations, see legend for Figure 1.

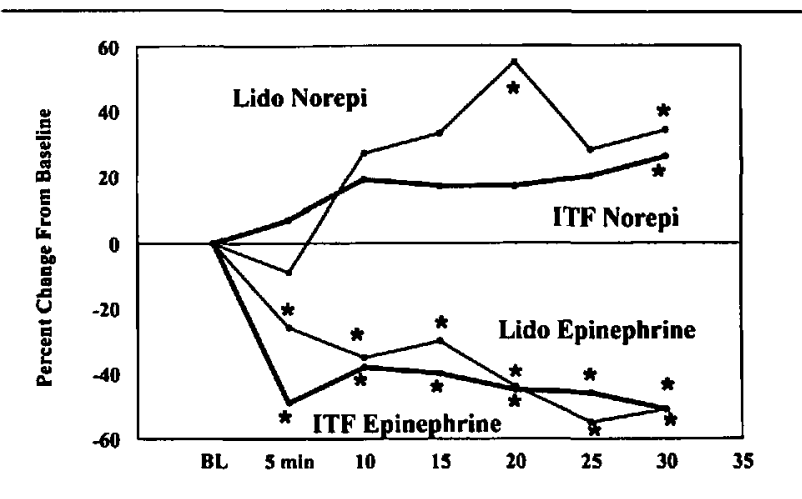

FIGURE 3 Percent change in maternal epinephrine and norepinephrine (Norepi) levels from baseline (BL) values. Data are mean \pm SD.

* significantly different from baseline within the group.

For other abbreviations, see legend for Figure 1. 
measured in blood samples drawn from an arm vein represent catecholamines released or processed by lung and other tissues. Peripheral venous norepinephrine concentration not only correlates with haemodynamic function in patients with congestive heart failure but also reflects sympathetic fibre activity. ${ }^{11}$ Thus, we feel confident that the antecubital venous samples used in our study were reliable.

The pain and anxiety associated with labour pain can cause an increase in maternal plasma catecholamine concentrations. ${ }^{12,13}$ These elevated maternal circulating catecholamine concentrations may adversely affect uteroplacental blood flow and, possibly, have a greater impact in situations in which there is preexisting placental hypoperfusion. Shnider et al. demonstrated that maternal stress elevates catecholamine levels, and this elevation is associated with an increase in maternal blood pressure and a decrease in uterine blood flow in pregnant ewes, ${ }^{14}$ a situation particularly detrimental to a compromised fetus. Catecholamines may cause blood to be shunted away from the uterus and placenta resulting in prolonged fetal hypoxia, as evidenced by abnormal electronic fetal heart monitoring tracings and abnormal fetal blood $\mathrm{pH}$ values. ${ }^{3}$ Excessive catecholamines can exert deleterious effects on labour as well. They can decrease the efficiency of uterine contractions, thus causing a prolonged dysfunctional labour. ${ }^{15}$ Myers ${ }^{16}$ reported that hypoxic and acidotic fetuses became more hypoxic and acidotic during acute maternal stress. Abboud $e t a l .{ }^{17}$ showed that preeclamptic patients had higher catecholamine concentrations than patients with an uncomplicated gestation. It is known that preeclamptic parturients have decreased uterine blood flow ${ }^{18}$ which puts them at increased risk for further undesirable fetal effects of elevated catecholamine levels.

Although we noticed a reduction in maternal plasma epinephrine concentrations following analgesia in both groups, the plasma norepinephrine concentrations stayed the same or increased slightly. The explanation for this differential effect is not readily apparent but may be related to the fact that epinephrine is the primary catecholamine associated with stress of labour. ${ }^{19}$ Norepinephrine plays an important physiological role in maintaining vascular tone and is released from peripheral nerve endings in response to voluntary and involuntary muscle activity. In fact, muscle activity and physical exercise are known to stimulate norepinephrine release to a much greater degree than does emotional stress. ${ }^{20}$ The work of labour is muscular activity of uterine contractions, which is not effected by analgesia thus there should little or no effect on norepinephrine concentrations. Norepinephrine is also important in maintaining haemodynamic homeostasis with changing posture. ${ }^{8}$ Thus, it is not surprising that pain relief did not cause a decrease in plasma norepinephrine concentrations.

The slight increase seen in norepinephrine concentrations may represent a response to vasodilatation. This homeostatic response is generally mediated via the aortic and carotid baroceptors. ${ }^{21}$ The baroceptor reflex is active with rapidly changing systemic pressure, especially around a mean arterial pressure of 100 mmHG. ${ }^{21}$ Conventional LEA causes vasodilatation by producing a sympathectomy. No consensus exists about the effect of ITF on systemic blood pressure. Although many believe that the decrease in systemic blood pressure following ITF administration is a result of pain relief, some attribute this decrease to an effect on the sympathetic system. It is interesting that Ramanathan et al..$^{22}$ reported a surge in norepinephrine concentrations with $\mathrm{T}_{6}$ sensory level achieved with epidural local anaesthetic injection.

The rapid decrease in maternal epinephrine concentrations following ITF administration in our patients raises an interesting question. It has been reported that the use of ITF labour analgesia might result in uterine hyperstimulation. ${ }^{23}$ Epinephrine, a beta-receptor stimulant, inhibits myometrial contractility and norepinephrine may increase uterine contractility ${ }^{24}$ via alpha-receptor stimulation. Thus, a sudden change in the concentration of one or both of these neuroaffector hormones may lead to uterine hyperstimulation.

In conclusion, we have shown that intrathecal fentanyl analgesia is as effective as epidural analgesia in providing pain relief for labour. Also, intrathecal fentanyl for labour analgesia leads to a decrease in circulating epinephrine concentrations in the labouring parturient, which is probably due to pain relief and, thus, a reduction in maternal stress.

\section{References}

1 Leighton BL, DeSimone CA, Norris MC, Ben-David B. Intrathecal narcotics for labor revisited: the combination of fentanyl and morphine intrathecally provides rapid onset of profound, prolonged analgesia. Anesth Analg 1989; 69: 122-5.

2 Mandell GL, Jamnback L, Ramanatban S. Hemodynamic effects of subarachnoid fentanyl in laboring parturients. Reg Anesth 1996; 21 : 103-11.

3 Lederman E, Lederman RP, Work BA Jr, McCann DS. Maternal psychological and physiologic correlates of fetal-newborn health status. Am J Obstet Gynecol 1981; 139: 956-9.

4 Abboud TK, Artal R, Henriksen EH, Earl S, Kammula $R K$. Effects of spinal anesthesia on maternal circulating catecholamines. Am J Obstet Gynecol 1982; 142: 252-4. 
5 Sbnider SM, Abboud TK, Artal R, Henriksen EH, Stefani SJ, Levinson G. Maternal catecholamines decrease during labor after lumbar epidural anesthesia. Am J Obstet Gynecol 1983; 147: 13-5.

6 Carruthers $M$, Conway $N$, Somerville $W$, Taggart $P$, Bates $D$. Validity of plasma catecholamine estimations. Lancet 1970; 1: 62-7.

7 Hjemdabl P. Catecholamine measurements by highperformance liquid chromatography. Am J Physiol 1984; 247: 13-20.

8 Robertson D, Johnson GA, Robertson RM, Nies AS, Shand DG, Oates JA. Comparative assessment of stimuli that release neuronal and adrenomedullary catecholamines in man. Circulation 1979: 59: 637-43.

9 van den Meiracker AH, Man in 't Veld AJ, Boomsma F, Schalekamp $M A$. Venous versus arterial forearm catecholamines as an index of overall sympathoadrenomedullary activity. Clin Exp Hypertens (A) 1989; 11(Suppl 1): 345-51.

10 Hörnchen U, Schüttler J, Stoeckel $H$. Influence of the pulmonary circulation on adrenaline pharmacokinetics during cardiopulmonary resuscitation. Eur J Anaesthesiol 1992; 9: 85-91.

11 Dimsdale JE, Zigler MG. What do plasma and urinary measures of catecholamines tell us about human response to stressors? Circulation 1991; 83(Suppl): II-36-42.

12 Lederman RP, McCann DS, Work B Jr, Huber MJ. Endogenous plasma epinephrine and norepinephrine in last-trimester pregnancy and labor. Am J Obstet Gynecol 1977; 129: 5-8.

13 Irestedt L, Lagercrantz $H$, Hjemdabl P, Hägnevik $K$, Belfrage $P$. Fetal and maternal plasma catecholamine levels at elective cesarean section under general or epidural anesthesia versus vaginal delivery. Am J Obstet Gynecol 1982; 142: 1004-10.

14 Shnider SM, Wright RG, Levinson G, et al. Uterine blood flow and plasma norepinephrine changes during maternal stress in the pregnant ewe. Anesthesiology 1979; 50: 524-7.

15 Lederman RP, Lederman E, Work BA Jr, McCann DS. The relationship of maternal anxiety, plasma catecholamines and plasma cortisol to progress in labor. Am J Obstet Gynecol 1978; 132: 495-9.

16 Myers RE. Maternal psychological stress and fetal asphyxis: a study in the monkey. Am J Obstet Gynecol 1975; 122: 47-58.

17 Abboud T, Artal R, Sarkis F, Henriksen EH, Kammula $R K$. Sympathoadrenal activity, maternal, fetal, and neonatal responses after epidural anesthesia in the preeclamptic patient. Am J Obstet Gynecol 1982; 144: 915-8.

18 Jouppila P, Jouppila $R$, Hollmén A, Koivula A. Lumbar epidural analgesia to improve intervillous blood flow during labor in severe preeclampsia. Obstet Gynecol 1982; 59: 159-62.

19 Lefkowitz R, Hoffman B, Taylor P. Neurohumoral transmission: the autonomic and somatic motor nervous systems. In: Gilman A, Rall T, Nies A, Palmer T (Eds.). The Pharmacological Basis of Therapeutics, 8th ed. New York: Pergamon Press, 1990: 102-4.

20 Dimsdale JE, Moss J. Plasma catecholamines in stress and exercise. JAMA 1980; 243: 340-2.

21 Guyton A. Textbook of Medical Physiology, 8th ed. Philadelphia: WB Saunders, 1991: 194-8.

22 Ramanathan S, Desai NS, Zakowski M. Systemic vascular uptake of epinephrine from the lumbar epidural space in parturients. Reg Anesth 1995; 20: 199-205.

23 Clarke VT, Smiley RM, Finster $M$. Uterine hyperactivity after intrathecal injection of fentanyl for analgesia during labor: a cause for fetal bradycardia? (Letter) Anesthesiology 1994; 81: 1083.

24 Zuspan FP, Cibils LA, Pose SV. Myometrial and cardiovascular responses to alterations in plasma epinephrine and norepinephrine. Am J Obstet Gynecol 1962; 81: $841-4$. 